\title{
Exclusive Breastfeeding Behavior Analysis at Hospital in Lampung Indonesia
}

\author{
Erlina Puspitaloka Mahadewi ${ }^{1 *}$, Intan Silviana Mustikawati ${ }^{2}$, \\ Mohamad Reza Hilmy ${ }^{3}$, Ade Heryana ${ }^{4}$ \\ 1,2,3,4 Universitas Esa Unggul, Jakarta Indonesia. \\ ${ }^{*}$ Corresponding author: \\ Email: erlina.puspitaloka@esaunggul.ac.id
}

\begin{abstract}
.
The present study reports the comprehensive study on the exclusive breastfeeding around support factors for successful activityof breastfeeding. In the three years lately UNICEF and WHO data on exclusive breastfeeding can reduce infant morbidity and mortality by more than $80 \%$. The coverage of infants who are exclusively breastfed is $65.35 \%$, the highest percentage is in West Nusa Tenggara $80.35 \%$ and the lowest percentage is in Papua $18.32 \%$. In Indonesia, there are $35.25 \%$ of $38 \%$ of children who are sick because they cannot receive exclusive breastfeeding. Exclusive breastfeeding is given when the baby is born until the age of 6 months. This study aims to determine knowledge, work and family support related to exclusive breastfeeding behavior in the work area of near with the RSIA PBH hospital in Lampung, Indonesia area in 2021. Using a cross sectional, a large sample of 120 respondents. Sampling in this study used a simple random sampling technique, and the chi-square test was carried out from January to August 2021. The results of the study were 95 respondents $(79,16 \%)$ mothers who did not give exclusive breastfeeding and 25 respondents (20.84\%) mothers who have exclusively breastfed their babies. There is a significant relationship between knowledge $(P=$ 0.000 and $P R=1.588)$, occupation $(P=0.000$ and $P R=1.995)$ and family support $(P=0.001$ and $P R=1.514)$ with exclusive breastfeeding behavior in the patients inside hospital work area in 2021. The paper presents the characterization support from the company, hospital and the closest family for exclusive breastfeeding is also very important. Based on the results of the study, it is recommended that health workers make innovations and new programs to increase exclusive breastfeeding.
\end{abstract}

Keywords: exclusive breastfeeding, family support, knowledge, works.

\section{INTRODUCTION}

Exclusive breastfeeding is needed in the first six months of life which contains many nutrients and is not contaminated by any substances. Early introduction of food that is prepared unhygienic and has low nutritional and energy content can cause children to be malnourished and infected by other organisms, so that the child has a low body resistance to disease from Ministry of Health in 2019[1]. The target of the Ministry of Health's Strategic Plan, regarding exclusive breastfeeding in 2019-2020 is $45 \%$, in Indonesia there are five provinces that have not yet reached the target of the Ministry of Health's Strategic Plan. Nationally, the coverage of infants who are exclusively breastfed is $61.33 \%$, the highest percentage of exclusive breastfeeding coverage is in West Nusa Tenggara (87.35\%), while the lowest percentage is in Papua (15.32\%). The United Nations Children's Found (UNICEF) and the World Health 
Organization (WHO) support this statement on breastfeeding in order to reduce infant morbidity and mortality[2]. The United Nations Children's Found (UNICEF) states that breastfeeding can save babies' lives, especially in developing countries, in developing countries exclusive breastfeeding can prevent under-five deaths by $90 \%$ due to diarrhea and acute respiratory infections[3].Breast milk is given for at least six months, during these six months the child is not given anything other than breast milk only. After the child is 6 (six) months old, solid food is given and continued breastfeeding is given until the child is two years old. The risk of stunting, obesity and chronic disease can be reduced by exclusive breastfeeding, exclusive breastfeeding can reduce infant mortality due to infection by $82 \%$ (WHO, 2018). In Indonesia, there are $31.36 \%$ of $37.94 \%$ sick children because they do not receive exclusive breastfeeding. Exclusive breastfeeding is very influential on future health, the impact of children when not exclusively breastfed is that they can experience stunting, obesity and other chronic diseases by Ministry of Health RI [4].

According to the Provincial Health Office in 2017-2020, exclusive breastfeeding in West Java as many as 349,968 babies aged 0-6 months out of 754,438 babies $0-6$ months (46.4\%) the coverage is still far from the national target of $80 \%$, although national coverage of $80 \%$, there are 2 (two) regencies or cities in Lampung that have exceeded the national target. One of the benefits of exclusive breastfeeding is to protect toddlers from malnutrition, obesity, stunting and diarrhea. The cases in the hospital at this study in 2021 were 1 person with poor nutrition, 55 obecity, 6 stunting and 72 cases of diarrhea (12.4\%) and 105 infants aged 12-24 months (18,2\%) who experienced diarrhea. The coverage of exclusive breastfeeding at the Lampung city Health Office (2020) is 8,271 babies with an average of $31.4 \%$ of the total number of 26,372 babies. The total number of babies obtained consisted of hospitals and health centers in the city of Lampung.

The working area around the hospital selected in this study has 25 district area a total of 578 babies, while only 122 infants $(21.1 \%)$. Lampung is $75 \%$ and the national target is $80 \%$ [5].Exclusive breastfeeding behavior is influenced by several factors, namely knowledge, work, and family support. This is in accordance with previous research conducted by based on the theory and related research that exclusive breastfeeding can affect the health of babies in the future. Exclusive breastfeeding can prevent obesity (overweight) and anemia due to iron deficiency in infants, reduce the risk of diabetes, cancer in children, and protect children from other chronic diseases of anemia and can meet the nutritional needs of children during their growth period as a start. in preparing the Human Resources (HR) of a nation in welcoming a good future[6].Knowledge is one indicator of the success of exclusive breastfeeding, is that mothers who have less knowledge are more likely not to breastfeed than mothers who have good knowledge. In addition to knowledge, according to work affects exclusive breastfeeding because mothers who return to work after maternity leave cause babies left to work to be given bottle milk or formula milk early so that they shift or replace 
breast milk. Family support according to mothers whose families are less supportive of breastfeeding. This paper presents the characterization support from the company, hospital and the closest family for exclusive breastfeeding is also very important. Based on the results of the study, it is recommended that health workers make innovations and new programs to increase exclusive breastfeeding[1][7].

\section{METHODS}

\section{Research methods}

The research is an applied study that uses a descriptive quantitative approach through survey research methods and seeks to prove the initial hypothesis which is called non-experimental hypothesis-testing research where the independent variables are not manipulated by the author.

\section{Research Design}

The analytical techniques selected to conduct this investigation are based on the suitability for characterizing of patients as the hospital customer. This research was conducted by distributing questionnaires as a research instrument Therefore, the instrument parameters must meet conservation standards regarding sampling the population, where minimum or no samples should be taken from that.

\section{Population and Sample}

In this study the population was taken from mothers who work and have babies aged 6-12 months with a sample size of 120 respondents. The sample calculation is carried out using the hypothesis testing formula for two proportions. The sampling technique in this study used the simple random sampling technique. This study uses a quantitative approach with the aim of getting an overview of the relationship between the independent variable and the dependent variable, study used a cross sectional design because in this study data collection was carried out at the same time. The data collection of information sources that will be used is in the form of secondary data, namely data on exclusive breastfeeding coverage in 2020-2021 and data on diarrhea, malnutrition, obesity and other diseases in 2021. Meanwhile, primary data is carried out by interview using a questionnaire for the variables of knowledge, occupation and family support. Furthermore, the data were analyzed univariately for each variable, while bivariate analysis was carried out by using the chi square statistical test using the statistic program with a significant level of $\mathrm{p}=0.05(\mathrm{CI}=95 \%)$.

\section{RESULT AND DISCUSSION}

Descriptions of respondents' research variables, namely the behavior of exclusive breastfeeding, knowledge, work and family support can be seen detail results are presented in Figure 1 and Figure 2 below.

\section{Description of Exclusive Breastfeeding Behavior}

Based on the figure 1, it is found that in the exclusive breastfeeding behavior variable, the highest proportion is found in respondents who are not exclusively 
breastfed, namely as many as 96 respondents (73.8\%), while the lowest proportion is in respondents who are exclusive breastfeeding, namely 34 respondents $(26.2 \%)$.

\begin{tabular}{lcc}
\hline Variables & Frequency & Procentage (\%) \\
\hline Exclusive Breastfeeding Behavior & & \\
No Exclusive Breastfeeding & 95 & 79,16 \\
$\quad$ Exclusive breastfeeding & 25 & 20,84 \\
Knowledge & & \\
Not Good & 62 & 48,0 \\
$\quad$ Good & 68 & 52,0 \\
Works & 53 & 48,5 \\
Working & 67 & 51,5 \\
$\quad$ Not Working & & \\
Family Support & 85 & 65,4 \\
$\quad$ Less Support & 35 & 34,6 \\
$\quad$ Good Support &
\end{tabular}

Fig 1. Overview of Each Variable in RSIA BPH Lampung City in 2021

Description of Mother's Knowledge about Exclusive Breastfeeding Behavior

Based on the table above, it is found that in the knowledge variable, the highest proportion is found in respondents who have less knowledge as many as 52 respondents $(48.0 \%)$ and the lowest proportion is found in respondents who have good knowledge as many as 68 respondents $(52.0 \%)$.

\section{Overview of Mother's Work}

Based on the table above, it is found that in the family work variable, the highest proportion is found in respondents who do not have a good job as many as 67 respondents $(51.5 \%)$, and the lowest proportion is found in respondents who have jobs as many as 53 respondents $(48.5 \%)$.

\section{Overview of Family Support for Mothers}

Based on table 1, it can be seen that from a total of 120 respondents, the highest proportion is found in respondents who have less family support as many as 85 respondents with a percentage $(65.4 \%)$, while the lowest proportion is found in respondents who have good family support as many as 35 respondents with percentage $(34.6 \%)$.

\section{Knowledge Related to Exclusive Breastfeeding Behavior}

Based on Figure 2 below, it can be seen that the highest proportion of respondents who have less knowledge are respondents who do not give exclusive breastfeeding, namely 65 respondents with a percentage of $88.7 \%$ and the highest proportion of respondents who have good knowledge are respondents who do not give exclusive breastfeeding, namely as many as 36 respondents with a percentage of $52.9 \%$.From the table above, it can also be seen that the $\mathrm{P}$ Value $=0.000$ with a value of $=0.05$ and the $95 \%$ CI degree of confidence is 1.588 (1.251-2.014). Based on these results, it can be seen if the $\mathrm{P}$ value $<0.05$. So it can be concluded that there is a relationship between knowledge and exclusive breastfeeding behavior. While the value 
of PR (Prevalence Ratio) of knowledge variable is 1.588 (1.251-2.014) which means that respondents who have less knowledge are 1.588 times not giving exclusive breastfeeding to their babies compared to respondents who have good knowledge.

\begin{tabular}{|c|c|c|c|c|c|c|c|c|}
\hline \multirow{3}{*}{ Variables } & \multicolumn{4}{|c|}{ Exclusive Breastfeeding Behavior } & & \multirow[b]{2}{*}{ otal } & \multirow{3}{*}{$\begin{array}{c}P \\
\text { Value }\end{array}$} & \multirow{3}{*}{$\begin{array}{c}\text { PR } \\
(95 \% \\
\text { CI }) \\
\end{array}$} \\
\hline & \multicolumn{2}{|c|}{$\begin{array}{l}\text { No Exclusive } \\
\text { Breastfeeding }\end{array}$} & \multicolumn{2}{|c|}{$\begin{array}{c}\text { Exclusive } \\
\text { Breastfeeding }\end{array}$} & & & & \\
\hline & $\mathbf{N}$ & $\%$ & $\mathbf{N}$ & $\%$ & $\mathbf{N}$ & $\%$ & & \\
\hline \multicolumn{9}{|l|}{ Knowledge } \\
\hline Not Good & 65 & $88,7 \%$ & 7 & $11,3 \%$ & 62 & $100 \%$ & \multirow{2}{*}{0,000} & 1,588 \\
\hline Good & 36 & $52,9 \%$ & 32 & $47,1 \%$ & 68 & $100 \%$ & & $\begin{array}{l}(1,251- \\
2,014)\end{array}$ \\
\hline \multicolumn{9}{|l|}{ Work } \\
\hline Working & 69 & $93,7 \%$ & 4 & $6,3 \%$ & 63 & $100 \%$ & 0,000 & \multirow{2}{*}{$\begin{array}{c}1,995 \\
(1,530- \\
2,601)\end{array}$} \\
\hline $\begin{array}{l}\text { Not } \\
\text { Working }\end{array}$ & 30 & $44,7 \%$ & 37 & $55,3 \%$ & 67 & $100 \%$ & & \\
\hline \multicolumn{9}{|l|}{$\begin{array}{l}\text { Family } \\
\text { Support }\end{array}$} \\
\hline $\begin{array}{l}\text { Less } \\
\text { Support }\end{array}$ & 58 & $74,1 \%$ & 22 & $25,9 \%$ & 85 & $100 \%$ & \multirow[b]{2}{*}{0,001} & $\begin{array}{l}1,514 \\
(1,15\end{array}$ \\
\hline $\begin{array}{l}\text { Good } \\
\text { Support }\end{array}$ & 29 & $64,4 \%$ & 21 & $35,6 \%$ & 45 & $100 \%$ & & $\begin{array}{c}9- \\
1,978 \\
\text { ) }\end{array}$ \\
\hline
\end{tabular}

Fig. 2. Proportion of Exclusive Breastfeeding Behavior with Independent Variables

\section{Occupations Related to Exclusive Breastfeeding Behavior}

Based on figure 2, it can be seen that the highest proportion of respondents who work are respondents who do not give exclusive breastfeeding, namely 69 respondents with a percentage of $93.7 \%$ and the highest proportion of respondents who do not work are respondents who give exclusive breastfeeding, namely 30 respondents with a percentage $55.3 \%$. From the table above, it can also be seen that the $\mathrm{P}$ Value $=$ 0.000 with a value of $=0.05$ and the $95 \%$ CI degree of confidence is 1.995 (1.5302.601). Based on these results, it can be seen if the $P$ value $<0.05$. So it can be concluded that there is a relationship between work and exclusive breastfeeding behavior. While the PR value (Prevalence Ratio) for the work variable is 1.995 (1.5302.601), which means that respondents who work 1.995 times do not give exclusive breastfeeding to their babies compared to respondents who do not work.

\section{Family Support Associated with Exclusive Breastfeeding Behavior}

Based on figure 2, it can be seen that the highest proportion of respondents who have less family support are respondents who do not give exclusive breastfeeding, namely 58 respondents with a percentage of $74.1 \%$ and the highest proportion of respondents who have good family support are respondents who do not give exclusive breastfeeding, namely as many as 29 respondents with a percentage of $64.4 \%$.From the table above, it can also be seen that the $\mathrm{P}$ Value $=0.001$ with a value of $=0.05$ and the 95\% CI degree of confidence is 1.514 (1.159-1.978). Based on these results, it can be seen if the $\mathrm{P}$ value $<0.05$. So it can be concluded that there is a relationship between 
family support and exclusive breastfeeding behavior. While the value of PR (Prevalence Ratio) for family support variable is 1.514 (1.159-1.978), which means that respondents who have less family support are 1.514 times not giving exclusive breastfeeding to their babies compared to respondents who have good family support.

\section{CONCLUSION \\ Knowledge}

Based of the conclusion and results of the study, it is known that there is a relationship between mother's knowledge and exclusive breastfeeding behavior. The results of statistical tests conducted on exclusive breastfeeding behavior in the working area of RSIA PBH Lampung in 2021 showed that there was a relationship between knowledge and exclusive breastfeeding behavior. Results of this study are in line with previous research that there is a significant relationship between the level of mother's knowledge about breastfeeding and exclusive breastfeeding. Result of Rizki Rahmawati Lestari's research (2018), which was conducted in the village of Petapahan, the working area of the Tapung Nursing Health Center, stated that there was a significant relationship between the knowledge factor of the respondents and exclusive breastfeeding. In addition, Iis Sriningsih's in 2011 research conducted at North Magelang Health Center and Jurang Ombo Health Center found that there was a relationship between respondents' knowledge of breastfeeding and exclusive breastfeeding[8].

The theory that supports this research is the theory put forward by Notoatmodjo, 2018 that knowledge is a very important element for the formation of one's behavior. The higher the knowledge of the benefits of breastfeeding, the better the practice of giving exclusive breastfeeding to the baby. Good knowledge is not only knowing and understanding, but knowledge must be applied, namely one's ability to use the material that has been studied. In this study, knowledge affects exclusive breastfeeding because the results of interviews using a questionnaire have good knowledge of mothers but they do not apply it to exclusive breastfeeding[9]. One of the factors that occur when mothers do not give exclusive breastfeeding to their children other than the mother does not apply directions or information regarding exclusive breastfeeding from health workers, because health workers only provide counseling in the form of providing information regarding exclusive breastfeeding without providing an overview or practice of exclusive breastfeeding. In addition, health workers also do not ask what problems occur to mothers who are breastfeeding so that mothers do not know how to overcome problems that occur while breastfeeding. Also, there is no counseling to the family who are around breastfeeding mothers to support and help mothers when breastfeeding problems occur.

Therefore, more mothers who have less knowledge and mothers who have good knowledge still do not give exclusive breastfeeding to their babies. So because of this, health workers should not only provide counseling in the form of information or 
provide material related to exclusive breastfeeding, but health workers should provide counseling using breastfeeding practices starting when the mother gives birth by practicing IMD (Early Breastfeeding Initiation) which is carried out in health facilities. the place where the mother gave birth[10]. Health workers are advised to be able to hold breastfeeding counseling more often in the form of providing information, asking questions about problems and providing solutions related to breastfeeding, besides that health workers can also accompany or evaluate exclusive breastfeeding to mothers who have babies aged 0 to 6 months.

Giving suggestions regarding practicing IMD (Early Breastfeeding Initiation) because the questions given the lowest score were on the question "According to the mother, when did the baby start breastfeeding?" with a percentage of $40.7 \%$, so that if health workers start by practicing IMD then it is very likely that the mother will know when the baby is breastfed after birth. Doing IMD can also prevent the culture of parents first giving honey or other fluids after the baby is born. In addition, health workers provide counseling not only to provide information but also to practice it so that breastfeeding mothers know how to give breast milk so that mothers can understand and practice breastfeeding their babies. Conduct breastfeeding counseling so that mothers understand more about exclusive breastfeeding, because the purpose of holding breastfeeding counseling is to provide more in-depth information, solve problems, assist and evaluate mothers who are breastfeeding babies aged 0-6 months so that mothers can exclusively breastfeed until babies are 6 (six months old) without providing additional food or drink[11][12].

\section{Work}

Based on statistical tests showed that the results carried out on exclusive breastfeeding behavior in the working area of RSIA PBH in 2021 showed that there was a relationship between work and exclusive breastfeeding behavior. The results of this study are in line with research conducted by Annisa Khoiriah \& Latifah (2018) at BPM Rusmiati Okta Palembang that there is a significant relationship between work and exclusive breastfeeding, and states that there is a significant relationship between maternal employment status and exclusive breastfeeding. This research is also supported by the theory put forward by that work can affect barriers to exclusive breastfeeding, because exclusive breastfeeding must be given until the baby is 6 months old but working mothers are given maternity leave and short maternity leave resulting in breastfeeding[13]. That should be given to infants until the age of 6 months cannot be achieved. So mothers who work provide other nutritional intake besides being breastfed directly by the mother to increase the intake of the baby while the mother is working.

Work affects exclusive breastfeeding in the working area of RSIA PBH because mothers who work and give exclusive breastfeeding from 120 respondents and 53 respondents who work only 7 respondents (5.83\%) who give exclusive breastfeeding to their babies[14]. According to the observations of researchers, the 
average work of mothers in the working area of hospitals in this research area is mothers who work in full-time offices and factories, even during the pandemic, so they have little time off and when they are active again, the mother spends her time in the workplace. work and leave the baby at home. Therefore, it is better if the mother's place of work supports the existence of child care, especially for mothers who are breastfeeding so that they can bring their children to work so that the child does not lose exclusive breastfeeding from his mother. In addition, if the workplace does not support bringing babies to work, the company should prepare a place for mothers to express breast milk and give time to send breast milk to their babies who are at home[15].

\section{Family support}

The results of statistical tests conducted on exclusive breastfeeding behavior in the working area of RSIA BPH Lampung in 2021 showed that there was a significant relationship between family support and exclusive breastfeeding behavior. The results of this study are in line with research that showed there was a relationship between family support and exclusive breastfeeding. The theory that supports family support in this study is that family support from the husband or closest family can increase the duration of breastfeeding until the baby is 6 months old and plays an important role in the success of exclusive breastfeeding. Mothers who feel supported, loved and cared for will have positive emotions that will increase the production of the hormone oxytocin so that milk production runs smoothly. Insufficient forms of family support can be caused by a lack of knowledge possessed by the husband or closest family, making it difficult to help or resolve problems regarding exclusive breastfeeding. Another cause of support is the husband or closest family who do not have time, which causes mothers to feel tired in taking care of children and feel unloved and loved, so that the milk that is issued is not smooth and maximal in breastfeeding[16].

Family support affects exclusive breastfeeding in this study because mothers who do not give exclusive breastfeeding are more likely to mothers who have less family support than mothers who have good family support[11]. Based on the results of interviews from this study using questionnaires, it was found that information on the form of family support was lacking in support such as providing reading materials to increase mother's information and literacy about breastfeeding, buying breastfeeding equipment and assistance to give expressed breast milk to her baby, lack of emotional support, namely by asking about problems that occur during breastfeeding and accompanying mothers during breastfeeding[8]. Giving expressed breast milk to babies requires equipment that must be prepared, therefore health workers provide understanding to the family to buy equipment such as breast pumps, bottles or breast milk plastics, the benefits of giving expressed breast milk can also prevent the occurrence of swollen breasts which will cause the mother to stop breast-feed. Therefore, mothers who are breastfeeding should be given more support by their husbands and their closest family so that the milk produced is smooth and can be given 
well to their babies. In addition, family knowledge must be increased. Health workers not only provide counseling to mothers who are breastfeeding, but also to their surrounding families on exclusive breastfeeding[17].

\section{Suggesstions}

According to the results of the conclusion study above, this study suggestion to increase maternal knowledge regarding exclusive breastfeeding, it is expected to provide counseling not only by providing material but also by practicing it with simulation methods and group discussions with a planned schedule. To increase exclusive breastfeeding for working mothers, the company is expected to facilitate more space and time for mothers who are breastfeeding. Also in addition, to increase family support related to exclusive breastfeeding, it is recommended that health workers provide material about the importance of family support and explain how to give expressed breast milk to babies. Occational counseling can be held on holidays or weekends from Hospital as healthcare provider is important to considering, so that the husband or closest family can accompany and participate in the counseling conducted by health workers. The contents of the counseling aside from the importance of exclusive breastfeeding to babies, health workers can also explain material about the importance of support from people around them for exclusive breastfeeding, and how to breastfeed other than directly from the mother's breast by giving expressed breast milk to the baby while the mother is not together[18].

\section{ACKNOWLEDGMENTS}

The authors are grateful to all parties for supporting this study project, especially thank to the hospital management and team research for all the the invaluable support and advices.

\section{REFERENCES}

[1] Ministry of Health of the Republic of Indonesia, "Indonesia Basic Health Research, $2018, " 2018$.

[2] WHO, "Together on the road to universal health coverage: A call to action," World Heal. Organ., 2017.

[3] R. Agustina et al., "Universal health coverage in Indonesia: concept, progress, and challenges," The Lancet. 2019, doi: 10.1016/S0140-6736(18)31647-7.

[4] The Joint Commission, "National Patient Safety Goals Effective January 1, 2016. Hospital Accreditation Program.," Jt. Comm., 2016.

[5] E. P. Mahadewi and A. Heryana, "Analisis Perilaku Pemberian ASI Eksklusif Di Puskesmas Bekasi,” Gorontalo J. Public Health., 2020, doi: 10.32662/gjph.v3i1.850.

[6] E. Puspitaloka Mahadewi, I. Putri Yanuarti, A. Heryana, and R. Kusumapradja, "The Effect of Exclusive Breastfeeding in Grogol Petamburan Health Center," 2020, doi: $10.5220 / 0009950026572662$.

[7] S. Folland, A. C. Goodman, M. Stano, S. Folland, A. C. Goodman, and M. Stano, "Economic Efficiency and Cost-Benefit Analysis," in The Economics of Health and 
Health Care, 2018.

[8] L. Trisnantoro, "Universal health coverage and medical industry in 3 Southeast Asian countries,” BMC Public Health, 2014, doi: 10.1186/1471-2458-14-s1-i3.

[9] B. Murti, "Asuransi Kesehatan Berpola Jaminan Pemeliharaan Kesehatan Masyarakat di Era Desentralisasi Menuju Cakupan Semesta," Inst. Heal. Econ. Policy Stud. (IHEPS). Univ. Sebel. Maret, 2011.

[10] A. S. Moriya, W. B. Vogt, and M. Gaynor, "Hospital prices and market structure in the hospital and insurance industries," Heal. Econ. Policy Law, 2010, doi: 10.1017/S1744133110000083.

[11] D. C. Hsia and C. A. Ahern, "Good quality care increases hospital profits under prospective payment," Health Care Financ. Rev., 1992.

[12] Joint Commission International, "JCI Accreditation Standards for Hospitals," Jt. Comm. Int. Accredit. Stand. Hosp., 2015.

[13] A. D. Intiasari, J. Hendrartini, and L. Trisnantoro, "Analisis pola pemanfaatan jaminan pembiayaan kesehatan era Jaminan Kesehatan Nasional pada peserta non PBI mandiri di wilayah perdesaan Kabupaten Banyumas,” Jkki, 2016.

[14] A. Ambarriani, "Hospital Financial Performance In the Indonesian National Health Insurance Era," McKinsey Q., 2014.

[15] W. Quentin et al., "Paying hospital specialists: Experiences and lessons from eight high-income countries," Health Policy (New. York)., 2018, doi: 10.1016/j.healthpol.2018.03.005.

[16] W. Quentin, D. Scheller-Kreinsen, M. Blümel, A. Geissler, and R. Busse, "Hospital payment based on diagnosis-related groups differs in Europe and holds lessons for the united states," Health Aff., 2013, doi: 10.1377/hlthaff.2012.0876.

[17] I. Mathauer and F. Wittenbecher, "Hospital payment systems based on diagnosisrelated groups: experiences in low- and middle-income countries," Bull. World Health Organ., 2013, doi: 10.2471/blt.12.115931.

[18] M. Z. Younis, P. A. Rivers, and M. D. Fottler, "The impact of HMO and hospital competition on hospital costs," J. Health Care Finance, 2005. 